\title{
Correction to: Intra-provincial Variation in Publicly Funded Mental Health and Addictions Services Use Among Canadian Armed Forces Families Posted Across Ontario
}

\author{
I. Garces Davila ${ }^{1}$ - H. Cramm ${ }^{2}$ - S. Chen ${ }^{3}$ - A. B. Aiken ${ }^{4} \cdot$ B. Ouellette ${ }^{5}$. \\ L. Manser ${ }^{5}$ P. Kurdyak ${ }^{3,6}$. Alyson L. Mahar ${ }^{1,3}$
}

Published online: 22 April 2020

(C) Springer Nature Switzerland AG 2020

\section{Canadian Studies in Population \\ https://doi.org/10.1007/s42650-020-00027-7}

Funding Information Funding for this study was provided in part through an unrestricted contract with the Canadian Forces Morale and Welfare Services.

\section{Compliance with Ethical Standards}

Conflict of Interest Chen and Garces declare that they have no conflict of interest. Aiken, Cramm, Kurdyak, and Mahar received an unrestricted research contract from the Canadian Armed Forces Morale and Welfare Services to complete this project. Cramm has received unrelated research funds from Calian. Ouellette and Manser are employed by the Canadian Armed Forces Morale and Welfare Services.

The online version of the original article can be found at https://doi.org/10.1007/s42650-020-00027-7

Alyson L. Mahar

alyson.mahar@umanitoba.ca

1 Department of Community Health Sciences, Rady Faculty of Health Sciences, University of Manitoba, 443 Brodie Centre, 727 McDermot Ave, Winnipeg, Manitoba R3E 3P5, Canada

2 School of Rehabilitation Therapy, Queen's University, Kingston, Ontario, Canada

3 ICES, Toronto, Ontario, Canada

4 Dalhousie University, Halifax, Nova Scotia, Canada

5 Canadian Forces Morale and Welfare Services (CFMWS), Ottawa, Ontario, Canada

6 Department of Psychiatry and Institute for Health Policy, Management, and Evaluation, University of Toronto, Toronto, Ontario, Canada 
Ethical Approval This study was completed in accordance with the ethical standards of the institutional and/or national research committee and with the 1964 Helsinki declaration and its later amendments or comparable ethical standards.

Consent For this type of study, formal consent is not required.

Disclaimer The funder did not have a role in data acquisition or data analysis. This study was supported by ICES, which is funded by an annual grant from the Ontario Ministry of Health and Long-Term Care (MOHLTC). The opinions, results, and conclusions reported in this paper are those of the authors and are independent from the funding sources. No endorsement by ICES or the Ontario MOHLTC is intended or should be inferred. Parts of this material are based on data and/or information compiled and provided by CIHI. However, the analyses, conclusions, opinions, and statements expressed in the material are those of the author(s), and not necessarily those of CIHI. 